\title{
Moralidade e sentido do trabalho para profissionais do sexo
}

\section{Morality and meaning of work for sex workers}

\section{Cíntia Sonale Rebonato}

Universidade de Passo Fundo (UPF)

email:cintiasonale@gmail.com

\section{Ana Paula Pessotto}

Universidade Regional Integrada (URI)

email:ana@uri.edu.br

\section{Shalimar Gallon}

Faculdade Meridional (IMED)

email:shalimar.canfield@imed.edu.br

\section{Jandir Pauli}

Faculdade Meridional (IMED)

email:jandir.pauli@imed.edu.br

\section{RESUMO}

Este estudo teve como objetivo analisar o sentido do trabalho para profissionais do sexo ante a imoralidade social do seu trabalho. Para isso, exploram-se como estes profissionais estabelecem boas combinações entre as transações econômicas e intimidade nas suas relações de trabalho a fim de dar sentido ao seu trabalho. A partir de um estudo qualitativo, foram entrevistadas oito profissionais e as informações coletadas foram analisadas com base na análise de conteúdo. O estudo mostrou que o sentido do trabalho está vinculado ao ajuste bem-sucedido entre transações monetárias e laços de intimidade. É este ajuste que permite criar suporte para dar sentido do trabalho, mesmo em um contexto de contestação moral. Constatou-se, também, que frequentemente as fronteiras entre intimidade e economia são transgredidas, exigindo destas trabalhadoras um esforço permanente para ajustar as relações econômicas no exercício do trabalho.

Palavras-Chave: prostituição; sentido do trabalho; circuitos econômicos; profissionais do sexo; negociação da intimidade.
This study aimed to analyze the sense of work for sex workers faced with the social immorality of their work. To do so, they explore how these professionals establish good combinations between economic transactions and intimacy in their working relationships in order to give meaning of their work. From a qualitative study, eight professionals were interviewed and the information collected was submitted to content analysis. The study showed that the meaning of work is linked to the successful adjustment between monetary transactions and intimacy ties. It is this adjustment that allows to create support to give meaning of work, even in a context of moral challenge. It was also observed that frequently the borders between intimacy and economy are transgressed, demanding from these workers a permanent effort to adjust the economic relations in the work.

Key-words: prostitution; meaning of work; economic circuits; sex workers; intimacy negotiation. 


\section{INTRODUCTION}

O exercício da profissão de trabalhador do sexo é similar ao modo de organização do trabalho em qualquer atividade (MARSHALL; MARSHALL, 1993; CHAPKIS, 1997; EDWARDS, 1997; ROBERTS, 1998; RODRIGUES, 2009). Trata-se de um trabalho como outro qualquer, no qual existem desafios a serem transpostos visto que a sociedade não o percebe como moralmente aceitável, sendo essa uma importante dimensão para que o trabalho tenha sentido (MORIN, 2001; MORIN; TONELLI; PLIOPAS, 2007).

Cabe ressaltar que o trabalho do profissional do sexo é regulamentado no Brasil pelo Ministério do Trabalho pela Classificação Brasileira de Ocupações (CBO), englobando as nomenclaturas de garota de programa, garoto de programa, meretriz, messalina, michê, mulher da vida, prostituta e trabalhador do sexo (BRASIL, 2002). Mesmo assim, a prostituição é uma prática marginalizada e trabalhadores permanecem sendo consideradas excluídas pela sociedade em geral (SILVA et al., 2013).

A prostituição tem sido frequentemente estudada, destacando-se estudos sobre a relação da prostituta com seu cliente (SOUZA, 2007; BURBULHAN; GUIMARÃES; BRUNS, 2012), motivações da busca pelo trabalho da prostituta (RUSSO, 2007), sobre a regulamentação da profissão ou como uma profissão (MARSHALL; MARSHALL, 1993; ROBERTS, 1998; EDWARDS, 1997; RODRIGUES, 2009; SOARES et al., 2015; ARRUDA et al., 2017; CARVALHO; OLIVEIRA, 2018), a trajetória de vida da prostituta e representações sociais (MOLINA; KODATO, 2005).

Entre os estudos sobre o trabalho das profissionais do sexo e suas repercussões sociais, o estudo de Rodrigues Filho (2014) mostra que o estigma carregado pelas prostitutas torna difícil a criação de laços afetivos na sociedade. Ele defende que a maneira como elas lidam com essas questões, tem forte impacto na saúde dessas profissionais, principalmente, no que se refere ao adoecimento por problemas psicológicos, devido à tendência de se instaurar um sofrimento patogênico na vida das profissionais do sexo.

Nesse contexto, Benoit et al. (2018) argumentam que a estigmatização social afeta vários aspectos da formação da identidade e interação social destas profissionais, criando um ambiente de isolamento e hostilidade, além de restringir o acesso destas trabalhadoras a uma gama de recursos e oportunidades, incluindo serviços judiciários e de saúde. Os autores afirmam que a consciência destes estigmas leva, muitas vezes, estas profissionais a negarem a divulgação de sua ocupação para outros, como provedores de cuidados de saúde, para minimizar a chance de preconceito relacionada à sua ocupação.

Os autores postulam que a consciência destes estigmas, muitas vezes, leva as trabalhadoras do sexo a negar a divulgação de sua ocupação, como para provedores de cuidados de saúde, para minimizar a chance de preconceito relacionada à sua ocupação. Estas profissionais geralmente aceitam discursos depreciativos e aplicam crenças negativas a si mesmas e ao seu trabalho (CARRASCO et al., 2017). Estas profissionais passam a acreditar que a violência e a discriminação são merecidas e "vêm com o território" (LYONS et al., 2017).

Nesse contexto, Silva et al. (2013) observam as dificuldades da profissão, uma vez que as profissionais do sexo são conscientes da sua não aceitação pela sociedade, mas direcionam o sentido de seu trabalho para outras questões, dentre elas a sobrevivência própria e dos familiares e a possibilidade de consumir aquilo que desejam, visto que muitas delas são mães e chefes de família. Assim, o presente estudo questiona: qual é o sentido do trabalho para os indivíduos que exercem uma profissão moralmente contestada?

Para embasar essa questão, o presente estudo traz o conceito de circuitos econômicos onde transações econômicas e intimidade frequentemente se misturam e mutuamente se sustentam, uma vez que todos os participantes usam a atividade econômica para criar, manter e negociar laços importantes que mantem com outras pessoas (ZELIZER, 2012). Os limites entre o que é aceitável e do que não é, o que é moral e o que não é, são erguidos pelas profissionais e nestes limites elas definem suas relações (ZELIZER, 2012). Diante desse cenário, é relevante compreender a forma com que os profissionais do sexo administram os conflitos entre dinheiro e intimidade, como estabelecem limites entre o que é permitido ou não e como estas relações são estabelecidas.

Tais limites são definidos em circuitos econômicos, através do que Zelizer (2012) denomina de 'boas combinações', não no sentido de uma simples barga- 
nha, mas das habilidades relacionais e do controle que as mesmas têm de desenvolver sobre suas emoções para executar bem a atividade, conquistar a clientela e manter uma relativa distância nas interações (ZELIZER, 2012). As combinações são importantes, pois nessas relações podem ocorrer trânsitos de estilos de afetos, já que existem estilos particulares em cada modalidade de intercâmbio sexual (FRANÇA, 2017). Afetos e transações circulam tanto na esfera profissional quanto na esfera privada, e os dois âmbitos não estão estritamente delimitados.

O trabalho das profissionais do sexo é exercido em um contexto em que o sexo é considerado uma mercadoria moralmente contestada (ERTMAN, 2009). Esta contestação provém de uma crença socialmente difundida de que sua liberação prejudicaria a ordem pública (STEINER; TRESPEUCH, 2014). Nesse contexto, este estudo tem por objetivo analisar como as prostitutas atribuem sentido ao trabalho, visto a imoralidade social do seu trabalho percebida pela sociedade. Para isso, exploram-se como as profissionais estabelecem boas combinações entre as transações econômicas e intimidade que circulam nas suas relações de trabalho a fim de dar sentido ao seu trabalho. Em outros termos, busca-se compreender com as prostitutas articulam as esferas da economia e da intimidade, tecendo boas combinações para o sentido do trabalho.

\section{O SENTIDO DO TRABALHO}

Atribui-se à Hackman e Oldhan (1975) os primeiros estudos relativos ao sentido do trabalho, relacionados à qualidade de vida. Para os autores, um trabalho tem sentido se for importante, útil e legítimo para quem o exerce, constituindo, assim, seis características de um trabalho que tem sentido: deve ser organizado e trazer resultados úteis; ser intrinsecamente satisfatório e desafiador, gerando prazer e satisfação para quem o realiza; ser moralmente aceitável; oportunizar relações interpessoais satisfatórias e o desenvolvimento de laços afetivos; garantir segurança e autonomia (emprego/ necessidades básicas); e estruturar o tempo, possuindo um início e um fim, horário e rotina diária e manter o indivíduo ocupado.
Além disso, Oliveira et al. (2004) identificaram o sentido do trabalho em três dimensões que se inter-relacionam para formar um conceito de trabalho, a saber: individual (coerência, alienação, valorização, prazer, desenvolvimento, sobrevivência e independência); organizacional (utilidade, organização do trabalho, relações interpessoais); e social (utilidade). Oliveira et al. (2004) e Morin, Tonelli e Pliopas (2007) concordam no que tange a clareza dos objetivos e valorização dos resultados por quem o realiza; a possibilitar a autogestão das atividades, garantindo a quem o executa lançar mão de suas capacidades para enfrentar desafios; a ser realizado respeitando as regras da sociedade, de acordo os valores sociais e morais que a regem. Assim, ambas as pesquisas reforçam a importância de condições de trabalho adequadas, que permitam ao indivíduo exercer sua autonomia e participação, contribuindo para seu desenvolvimento pessoal.

Ademais, um trabalho para ter sentido precisa garantir a sobrevivência do indivíduo, sua inserção no meio social, proporcionar a interação com outras pessoas, gerar sensação de pertencimento e utilidade para a organização e sociedade e o desenvolvimento, valorização e autorrealização (TOLFO; PICCININI, 2007). Para tanto, o sentido do trabalho relaciona-se com elementos como autonomia, reconhecimento, desenvolvimento e crescimento (MORIN, 2001; OLIVEIRA et al., 2004; MORIN; TONELLI; PLIOPAS, 2007; TOLFO; PICCININI, 2007; RODRIGUES; BARRICHELLO; MORIN, 2016). Isso é corroborado na pesquisa de Nascimento, Santos e Pinto (2017) com agentes funerários, na qual os entrevistados apontaram que encontram sentido em seu trabalho por meio da valorização e reconhecimento do serviço prestado pelos clientes.

No caso do trabalho sexual, os indivíduos que o exercem sofrem discriminação e preconceito pela natureza de seu trabalho, além do estigma social (KOKEN, 2012; SANDERS, 2017; WEITZER, 2017). Tomando como base a perspectiva de um trabalho com sentido proposta por Oliveira et al. (2004), Morin (2001) e Morin, Tonelli e Pliopas (2007), a qual sugere que para possuir sentido um trabalho precisa ser moralmente aceito, autores como Silva et al. (2013), Silva e Cappelle (2015) e Corrêa e Holanda (2012) ponderam que apesar de os profissionais do 
sexo serem um trabalho estigmatizado, tida como imoral, ele possui um sentido, muitas vezes, associado a sobrevivência, a busca da independência e status social.

\section{ECONOMIA, SEXO E INTIMIDADE}

$\mathrm{Na}$ tradição da análise social, intimidade e economia foram classificadas como esferas separadas, visto a dicotomização do mundo em mercado e não mercado (racional versus pessoal; público versus privado; eficiente versus sentimental; macho versus fêmea; sexo versus amor) (ZELIZER, 2012). Assim, a análise sociológica não deve somente ater-se ao estudo das empresas e mercados, ao contrário, deve ir além, reconhecer processos e relações sociais no âmago da economia, como a intimidade, preocupando-se da mesma maneira com as formas de produção, consumo, distribuição e trocas (ZELIZER, 2008).

Ressalta-se que a noção de intimidade proposta por Zelizer $(2000,2005)$ abarca a perspectiva da confiança, da reciprocidade e amizade, consistindo em uma probabilidade analítica para superação dos denominados mundos hostis. Sendo assim, há duas formas de intimidade: uma que sustenta a transmissão de informações confidenciais e potencialmente 'minadas' e outra que se refere a vínculos estreitos duráveis entre duas pessoas (PAULI; ROSENFIELD, 2017). As transferências econômicas acontecem nesta intimidade, exigindo dos envolvidos um trabalho relacional para o ajuste dos limites entre o aceitável e o imoral.

Frente a esse contexto, emerge a noção de circuito econômico como 'lugar' onde as transações efetivamente acontecem, tornando-se uma configuração importante e mais complexa dos laços sociais (ZELIZER, 2012). Assim, o papel do circuito econômico é permitir a circulação de acordos, práticas, informações, instrumentos de troca e símbolos partilhados em um ambiente. Em síntese, compete aos envolvidos na transação definirem o conteúdo moral e os limites do circuito. Isto exige que os profissionais do sexo, após terem acesso à intimidade dos clientes, a transformem em confiança a partir de laços de reciprocidade para fortalecer a relação cliente-profissional, conferindo significados do dinheiro e propondo 'boas combinações' entre intimidade, cultura e racionalidade instrumental (ZELIZER, 2005, 2009).

Corroborando Zelizer (2006), França (2014) observa que no mercado do sexo, essa demarcação também existe. Ademais, formas distintas de transações alteram tanto a interação entre profissional-cliente quanto seu status. Na prática, são os múltiplos arranjos que o profissional do sexo efetua em suas relações com clientes e com parceiros pessoais que permitem 'boas combinações' entre dinheiro e atividade econômica (FRANÇA, 2014).

É, portanto, o sentido do trabalho a partir dos ajustes entre intimidade e dinheiro que se busca apreender neste estudo. Esta questão está pautada na possibilidade de reflexão sobre a conexão entre o afeto, sexo e dinheiro em diversos contextos sociais e a multiplicidade de sentimentos e motivações implicados no circuito econômico que engloba o trabalho do sexo.

\section{PROCEDIMENTOS METODOLÓGICOS}

A presente pesquisa é de abordagem qualitativa, uma vez que buscou analisar a percepção dos profissionais do sexo quanto ao sentido atribuído ao seu trabalho e as distintas combinações entre sentimentos, sexualidade e interesses econômicos delimitados neste circuito econômico. A pesquisa foi realizada em dois estabelecimentos (nomes fictícios utilizados de Estabelecimento A e Estabelecimento B) no norte do estado do Rio Grande do Sul (RS).

A coleta das informações foi realizada por meio de entrevista com oito profissionais do sexo escolhidas pelo critério de acessibilidade, a partir da técnica de bola de neve. Em função disso, o acesso às entrevistadas do sexo feminino se mostrou mais fácil, embora não se tenha buscado fazer distinção entre sexo, idade, escolaridade e renda. Os nomes utilizados para se referir às profissionais do sexo são fictícios para preservar a identificação das entrevistadas. Mônica, Patrícia e Monique trabalham no Estabelecimento A e Horrana, Angel, Castelhana, Rubi e Jéssica trabalham no Estabelecimento B. 
As entrevistas foram realizadas à tarde no local de trabalho das participantes, de acordo com a disponibilidade de cada profissional, nos meses de julho e agosto de 2017. Entretanto, a entrevista de Patrícia ocorreu após às 20 horas, durante o horário de funcionamento do estabelecimento.

As entrevistas tomaram como base um roteiro semiestruturado composto por 23 perguntas que englobam questões sobre os sentidos do trabalho e a permeabilidade entre os tipos de relações que envolvem intimidade e troca econômica no circuito econômico do sexo.

As entrevistas tiveram em média a duração de 40 minutos e foram gravadas em áudio. Atentando aos padrões éticos em pesquisa, antes do início de cada entrevista foram apresentados os objetivos do estudo; informado sobre caráter voluntário da participação; explicado o roteiro e duração da entrevista; e, que em caso de constrangimento poderiam optar por não responder à pergunta ou suspender a entrevista a qualquer momento. Foi solicitado para as participantes que assinassem um termo de consentimento livre e esclarecido. As gravações somente tiveram início após o consentimento das entrevistadas.

Para a análise das informações, foi utilizada a técnica de análise de conteúdo (Bardin, 2009). Em um primeiro momento, foi realizada a transcrição das entrevistas e uma leitura flutuante a fim de estruturar as categorias. A análise partiu de duas macrocategorias a priori: o trabalho da profissional do sexo e sentido do trabalho. Conforme o trabalho de categorização era desenvolvido, as categorias primárias foram surgindo naturalmente e sendo organizadas com base no que foi abordado no referencial teórico. Assim, a primeira macrocategoria descreve o funcionamento do trabalho, o profissionalismo, percepção sobre o trabalho e como a sociedade percebe as profissionais do sexo. A segunda macrocategoria aborda a remuneração, sobrevivência, relações sociais, autonomia, prazer em realizar a atividade e segurança no trabalho. Após essas análises, a categoria final compõe a análise das esferas econômicas e de intimidade a partir de boas combinações para o sentido do trabalho.

\section{ANÁLISE DAS INFORMAÇÕES COLETADAS}

A análise das informações está organizada na descrição do trabalho da profissional do sexo e na análise do sentido do trabalho. A parte final dessa seção é composta pela a análise das esferas econômicas e de intimidade a partir de boas combinações para o sentido do trabalho.

\subsection{As características do trabalho da profissional do sexo}

O Estabelecimento $\mathrm{A}$ inicia as atividades às 13 horas e 30 minutos, sem horário fixo para seu encerramento, normalmente, em torno de cinco horas da manhã. A negociação dos programas acontece entre a profissional e o cliente, na qual é combinado o preço do programa, tempo de duração, modalidades de sexo a serem realizadas e valor do aluguel do quarto. O montante é pago pelo cliente, em dinheiro, à prostituta antes da realização do programa. Não é cobrado das prostitutas qualquer tipo de porcentagem sobre o programa, o único valor repassado para a dona do estabelecimento é proveniente do aluguel $(\mathrm{R} \$ 30,00)$ dos quartos. Basicamente, o lucro do estabelecimento obtido advém do comércio de bebidas, produtos do bar e aluguel dos quartos.

A prostituição reproduz hierarquias sociais e as próprias profissionais dividem e atribuem valores diferentes às modalidades de comércio do sexo (FRANÇA, 2014, 2017). No Estabelecimento A, os tipos de programas possuem denominações e características diferentes. O valor tabelado é denominado como mínimo da casa e todos os programas só ocorrem a partir desse valor. O programa denominado de completo inclui sexo oral, várias posições de sexo vaginal, dentre outras modalidades de sexo, com duração média de 30 a 40 minutos. O programa definido como básico inclui a felação e, dependendo do caso, uma posição de sexo vaginal, com duração média de 15 minutos.

O Estabelecimento B funciona a partir das 22 horas, no entanto, as garotas de programa, como preferem ser chamadas, que residem na boate atendem alguns clientes fixos em outros horários, $\mathrm{o}$ que ocorreu durante a entrevista, quando Horrana 
atendeu um cliente após a entrevista. O estabelecimento só encerra o expediente quando for atendido o último cliente. Atualmente, moram doze garotas no estabelecimento.

Os programas no Estabelecimento B são tratados entre as prostitutas e o cliente, mas o valor mínimo da casa é $\mathrm{R} \$ 150,00$, tendo de 15 a 30 minutos de duração. $O$ valor é acertado antes da realização do programa e pago por meio de dinheiro ou cartão de crédito. As profissionais recebem comissão sobre as doses de bebida alcoólicas consumidas pelos clientes. A venda de bebida é comissionada no valor de $\mathrm{R} \$ 75,00$ por cada garrafa de espumante consumida. Os outros tipos de bebidas são cobrados por doses, cada dose é $\mathrm{R} \$ 15,00$. O aluguel dos quartos é de responsabilidade dos clientes que custam entre $\mathrm{R} \$ 50,00$ e $\mathrm{R} \$ 150,00$, variando em função do valor do programa cobrado pela garota de programa.

$\mathrm{Na}$ prostituição, entende-se como trabalho as relações sexuais que sucedem em pagamento, troca de serviços e controle de tempo. Nesse estudo, estão inseridas as formas, as regras e meios de satisfação e fidelização do cliente, sendo o quarto o posto de trabalho. Ademais, o tempo de trabalho pode ser melhor remunerado, desde que seja acordado antecipadamente com o cliente.

Monique que trabalha no Estabelecimento A conta que há colegas que fazem o programa completo por $\mathrm{R} \$ 30,00$, sendo que este valor é estipulado pelo programa denominado de 'básico' e, de acordo com ela, existe grande concorrência entre as colegas, em função de não ter um 'mínimo da casa' estabelecido, dificultando a relação de trabalho entre elas. A concorrência nesta profissão promove práticas distintas das descritas, consideradas pelas entrevistadas como bizarras e desprezíveis, o que demonstra que as regras (referentes ao que pode e não pode no exercício da profissão) se mantêm, apenas mudam em tempos de crise e acentuada competição por um mercado atualmente saturado. Tal situação também é descrita em estudo realizado com travestis brasileiras na Espanha sobre o circuito econômico do sexo (PELÚCIO, 2012).

Corroborando essa perspectiva, Angel observa que "nada é de graça. Eles sabem, vão ter que dar dinheiro por qualquer coisa que eles forem fazer, entendeu? Então, eu deixo a realidade estampada! E, tem gurias que não. Preferem ter aquele namoradinho fixo. Dá uma vez, na outra não cobra nada. Não, eu sou muito profissional". Assim, a profissional do sexo se diferencia pelas regras do seu trabalho, nas quais tudo o que for feito tem o seu valor monetário. Assim, o amor não faz parte das descrições do trabalho das profissionais do sexo.

Assim, embora a sociedade perceba o trabalho das profissionais do sexo como algo fácil (SILVA et al., 2013), para as entrevistadas, o trabalho exercido "não é uma coisa fácil, é rápido. Num dia, tu ganha o que um trabalhador normal demora para ganhar em trinta dias". Desse modo, não percebem a imoralidade e a facilidade do seu trabalho, justamente por envolver diversos aspectos que permeiam outros tipos de trabalho, tais como negociação e reclamação de cliente, como aponta Angel: "quando tu acertou ali o programa, e daí chega no quarto e o cara não gostou de ti, tu não tem culpa, daí ele pega e quer o dinheiro de volta. Entrou no quarto, fez o terereu, não tem o que fazer. Já aconteceu comigo, duas vezes, de o cara querer o dinheiro de volta".

Rubi compartilha dessa percepção e relata que "uma vez cheguei no quarto e um cliente começou a dizer 'agora sou eu que mando, eu estou pagando e vou fazer o que eu quiser' e eu disse que não, que já havíamos combinado o que ia e o que não ia fazer". Assim, a negociação do serviço vendido tem que ser clara e acertada previamente para que não ocorra equívocos quanto ao trabalho oferecido, como relata Castelhana: "tem coisas que as outras meninas fazem que eu não faço. Uns gostam de fazer amor de forma violenta e pedem demais, mas eu digo que não sou assim e digo que busque outra menina. Normalmente, eu já combino antes de ir para o quarto, já digo o que faço e o que não faço".

Ademais, como todo trabalho, tem um custo (do aluguel do quarto e de embelezamento da profissional), pois "a gente gasta com salão, a gente é super cheirosa, produtos caros" (Jéssica). Nessa mesma perspectiva, a profissional mobiliza diferentes habilidades e comportamentos frente aos diversos tipos de clientes que aparecem, visto que ela não escolhe o cliente que vai atender, como relata Jéssica: "um dia você vai ficar com um senhor de idade, outro dia com um mais novinho, diariamente isso é marcante. Cada dia um rosto diferente, uma pessoa diferente, um jeito diferente. A gente tem de ser uma pessoa diferente a 
cada momento". Ademais, constantemente as profissionais do sexo desenvolvem diversas técnicas e habilidades para ganhar mais, como por exemplo, criar estratégias a fim de incentivar o consumo de álcool pelo cliente, envolvimento emocional e fidelização do cliente, como relata Monique:

Quando o cliente chega e não vai para o quarto direto, daí eu sou carinhosa, então, ele bebe, bebe um pouco mais, conversa, conta da vida, da família. A maioria é casado, briga com a mulher e vem para cá. A gente deixa ele falar, se insinua, dança, ele bebe mais e quando vai para o quarto, às vezes nem acontece, a gente fica só conversando, fica até amigo, daí ele volta de novo.

Na prostituição, esse tipo de habilidade é denominado de "malandragem" (FRANÇA, 2017) e a simulação do beijo na boca também é uma habilidade desenvolvida pelas entrevistadas. O beijo na boca não faz parte do trabalho das entrevistadas porque se o cliente chegar a beijar, ele pode satisfazer as suas necessidades e não vir a fazer o programa, mas ao mesmo tempo, as profissionais têm que envolver o cliente ao ponto de despertar o interesse de pagar pelo serviço. Angel relata a sua percepção: "quando o cara vai beijar, eu já vou virando o rosto. Na verdade, tem que dá uma enganada porque se não o cara não vai ficar. A gente está louca para ganhar o dinheiro e goodbye, tem que dar uma iludida”.

Os relatos mostram que as profissionais do sexo percebem o seu trabalho como outro qualquer em função de mobilizarem habilidades, desenvolverem estratégias de vendas de serviços e produtos, terem regras estipuladas com os clientes, terem um custo para que o serviço seja prestado e envolverem uma transação monetária, negociação e fidelização do cliente. Ademais, o serviço prestado não está relacionado somente ao sexo, mas também por envolver dança, conversa e venda de bebidas alcoólicas.

\subsection{Sentido do trabalho}

Conforme exposto anteriormente, os depoimentos das entrevistadas mostram que a prostituição é percebida como um trabalho qualquer que por meio da remuneração garantem a sua sobrevivência, corroborando os estudos de Hackman e Oldhan (1975), Morin, Tonelli e Pliopas (2007) e Oliveira et al. (2004) que indicam que o trabalho tem sentido quando garante a sobrevivência. Isso também contribui com a pesquisa de Silva et al. (2013) de que as prostitutas encontram sentido no seu trabalho em função da sua sobrevivência e dos familiares.

As entrevistadas relatam a falta de estrutura familiar e financeira desde a infância, coerente com o contexto apontado por Silva et al. (2013), Mônica relata que "não nasci puta". Esse contexto é explicado no depoimento de Monique: "meu marido faleceu, eu não tinha dinheiro, dois filhos pequenos. Então, tentei trabalhar de doméstica, de cozinheira, mas mesmo assim foi necessário vender meu terreno. Hoje, eu tenho meu bar, sustento meus filhos, tenho meu companheiro".

A Castelhana complementa essa percepção ao relatar que faz programa por uma questão de sobrevivência, mas que "gostaria de mudar de vida, não quero me acostumar a esta vida e buscar um outro tipo de trabalho mais decente. Ter uma vida normal porque não gosto disso que faço" (Castelhana). Assim, contrariando os estudos de Hackman e Oldhan (1975), Morin, Tonelli e Pliopas (2007) e Oliveira et al. (2004), ser profissional do sexo não é um trabalho que traz prazer para as entrevistadas, pois o "o melhor do nosso trabalho é o dinheiro porque a maioria dos clientes a gente não gosta" (Jéssica).

A Rubi compartilha dessa percepção, embora confunda o prazer do trabalho com o prazer sexual: "quando você está bebendo e conversando na boate é bacana porque é como se você estivesse numa balada, mas quando vai para o quarto não é muito legal porque quando você não faz por amor, não tem prazer, então, você vai só pelo dinheiro". A falta de prazer na realização da atividade laboral e do prazer sexual também é exposta no estudo de Silva et al. (2013) desmistificando o fato de que toda prostituta é ávida por sexo.

Assim, o ato sexual é um fator de desconforto na profissão e as entrevistadas fazem uso de álcool para desenvolver o seu trabalho, como relata Patrícia: "ter que dormir com o cliente, aguentar a noite inteira. A gente tem que beber muito, sem contar outras coisas que tem que fazer, se não, não tem como. Uns tu tem nojo, uns são sujos, mas não dá para escolher. Às vezes, tu quer sair dessa vida”. A Castelhana relata que é comum ter colegas de trabalho que usam drogas, 
fumam e bebem em função do ambiente de trabalho, bem como por influência dos clientes que oferecem bebidas e drogas.

Na mesma direção, a Castelhana enfatiza os riscos de saúde e violência física que envolvem a profissão: "para mim é difícil porque ir para o quarto com uma pessoa que se droga e que pode te pegar é muito ruim. Estou nisso há um ano e, todavia, não me acostumo, é difícil". Além disso, tem a questão das doenças que estão em torno da atividade, sendo que as profissionais percebem entre elas o profissional e o amador pelo modo como se protegem dos perigosos da profissão, como relata Angel: "a garota profissional, ela não beija nem na boca, não faz sem camisinha, não faz oral sem camisinha, nada. É tudo prevenido, tudo. Porque tem várias coisas, tem doenças que tu pode pegar via oral e sexualmente transmissível entendeu?". Essa perspectiva mostra a importância de que o trabalho seja realizado de modo que mantenha a segurança, saúde e integridade dos indivíduos, corroborando Morin (2001) sobre as condições de trabalho para que o trabalho tenha sentido.

A segurança no trabalho também emerge frente às relações de coleguismo que elas desenvolvem para se protegerem dos excessos dos clientes. Monique relata o episódio que aconteceu com a colega Caren (que não participou da pesquisa), no qual emergiu como um momento de conscientização sobre a importância de elas desenvolverem estratégias coletivas para realizarem o trabalho:

A gente se dá bem. Tem aquela que não dá, mas a gente se ajuda. Depois que o cliente bateu na Caren e obrigou ela fazer um monte de coisas e ela ficou bem machucada, a gente se uniu um pouco. Agora uma sempre chama a outra e diz que está indo lá para baixo. A gente marca o tempo e bate na porta. Se o cara tá muito bêbado a gente chama antes. (...) A gente levou para o hospital, não tem como fazer nada, a polícia não quer nem saber. Ela ficou bem machucada.

Em ambos os estabelecimentos foi relatado relações de amizade, colaboração como também, competição, individualismo, semelhante ao que acorre em qualquer organização. Assim, os relacionamentos interpessoais são importantes para o sentido do trabalho para as entrevistadas, corroborando o estudo de Morin (2001). Os depoimentos mostram que as relações humanas nem sempre se desenrolam de forma positiva com os clientes, embora o relacionamento com as colegas de profissão e com os proprietários dos estabelecimentos seja bom, como relata Rubi:

Todas as casas que eu fiquei sempre fui muito bem tratada, mas esta em especial tem alguns diferenciais: cada garota tem o seu quarto, temos duas cozinheiras que preparam as refeições, somos tratadas esplendidamente. Recebemos certinho, não desconta nada, hospedagem, alimentação.

Os relatos das entrevistadas também mostram que ser profissional do sexo implica em estar isolada da sociedade, em função dos horários de trabalho e afastamento do local do trabalho. Esse contexto faz com que sintam saudade da família e dos filhos, se sintam sozinhas e tenham dificuldade de desenvolverem laços afetivos sociais, como relata Jessica: "o que me faz sofrer é a falta do meu filho, da minha família. Quando o movimento está meio fraco, fico 20 até 30 dias por lá”. Horrana complementa essa percepção:

O mais difícil, às vezes, é se sentir sozinha porque tu vive aqui, tu está aqui direto, daí tu se sente sozinha. Tua vida é aqui, não tem como tu fazer duas vidas. Daí é a carência, é carência de ter alguém, sabe. Têm dias que dá vontade de sair daqui gritando e chorando porque é difícil. Que nem eu, estou longe da minha família, mas tu tem que saber dividir, tem que aprender lidar com isso [a solidão].

O sentido do trabalho para as profissionais do sexo é visivelmente atrelado à remuneração do trabalho, a qual permite que as entrevistadas obtenham os bens materiais desejados, corroborando os estudos de Silva et al. (2013), como relata Angel: "estou aqui para ganhar meu dinheiro e conquistar os objetivos que te falei. $\mathrm{O}$ meu apartamento, fazer uma faculdade de estética e abrir a minha estética, a minha loja, ter o que é meu". Já Monique relata os bens que conquistou com a profissão: "tenho meu bar, sustento meus filhos, tenho meu companheiro, vou até fim do ano e saio dessa vida. Eu consegui muita coisa, tenho um teto para abrigar meus filhos". Angel complementa essa percepção:

Uma vez quebrou meu celular e eu, como não estava trabalhando, estava trabalhando só fazendo maquiagem e design de sobrancelhas, o rendimento estava pouco. Daí, eu comecei a conversar com a minha mãe e tal e ela: 'tá, eu vou te levar [para fazer programa]'. A grana estava curta e eu queria um 
celular, o que não deixa de ser uma necessidade, né? O que eu ganhava como maquiadora não dava.

Esses depoimentos corroboram o entendimento da autonomia dos indivíduos no sentido do trabalho que está intimamente ligado ao âmbito financeiro e a possibilidade de melhorar a qualidade de vida (MORIN, 2001). Além disso, para as entrevistadas, a autonomia também está associada à possibilidade de sair da profissão, não depender de outras pessoas para tomar suas decisões nem de quando exercer as suas atividades profissionais, corroborando o estudo de Silva et al. (2013), como relata a Patrícia: "eu tenho liberdade, trabalho quando eu quero. Hoje, atendo mais os fixos, sei que, no mínimo uma vez por semana, eles vão lá. É garantido. Hoje, eu faço os meus horários. Quando precisei levar um filho no médico, eu pude. Na época de doméstica, o patrão não gostava”.

A busca pela autonomia é visível nos depoimentos das profissionais, porém trazendo uma dimensão díspar das tratadas por Morin (2001), Oliveira et al. (2004) e Morin, Tonelli e Pliopas (2007), uma vez que para as entrevistadas a autonomia também está ligada à independência do marido, à saída da casa dos pais, como aborda o estudo de Silva et al. (2013).

Para as entrevistadas, o ingresso na profissão não abalou o relacionamento familiar, entretanto, nos depoimentos de algumas profissionais, a maior resistência à profissão foi por parte da família. Monique relata que "a família fala mal de ti. Ficam cochichando, falando para os outros que tu foi para zona, se perdeu". Atualmente, afirmam contarem com o apoio da família, exceto Monique que relata que o filho mais velho "disse: 'mãe para, vai que passe um amigo meu e te veja lá na frente. Vai ficar feio para mim'. A família te vira a cara, tem gente que nem te olha, mas eu digo, é de lá que vem o dinheiro para eu pagar as contas".

As entrevistadas entendem que a sociedade as considera putas e não como pessoas que exercem uma atividade, como relata Monique: "aqui a gente não é garota de programa, aqui a gente é puta, é mulher de zona. Garota de programa é a universitária, a secretária. As minhas parentes, minhas sobrinhas, tias, foram as que mais me ofenderam. Comentaram com todo mundo, como se elas fossem santas". Para as entrevistadas, fazer sexo sem envolver uma tran- sação financeira deveria ser alvo de desrespeito social, enquanto que a atividade remunerada não pode ser comparada a tal situação, como relata Jéssica: "puta é essas meninas, que dão de graça na balada, essas, sim, são putas. Se tu parar para pensar, a mais puta é aquela que dá de graça, vai para balada, beija na boca de todo mundo" (Jéssica).

Patrícia relata que as pessoas da sociedade percebem o seu trabalho como o "pior possível". Embora as entrevistadas tenham consciência do preconceito, elas não escondem o que fazem e entendem que a prostituição é um trabalho, onde elas oferecem um serviço. Elas ressaltam que são bem atendidas nos estabelecimentos comerciais, como observa Horrana: "em relação a qualquer lugar, restaurante, não tem aquele negócio de preconceito".

No entanto, a questão do preconceito é um tanto divergente entre as entrevistadas, uma vez que algumas sentem vergonha e incomodadas frente à reação das pessoas, como relata Rubi: "hoje, ainda a profissão tem a imagem de mulher vulgar. Sofro muito preconceito, cochichos, conversinha. Quando você vai comprar uma roupa, você é atendida diferente, não fazem questão de vender". Essa questão do atendimento nas lojas contraria os achados da pesquisa de Silva et al. (2013), na qual as entrevistadas são bem atendidas em lojas em função de consumirem bastante e pagarem à vista.

Os depoimentos mostram que, de modo geral, a sociedade não considera a prostituição uma profissão moral, fato corroborado nos estudos de Rodrigues (2010), Silva et al. (2013) e França (2014). Elas relatam que a maior hostilidade ocorre por parte das mulheres, pois "tem umas mulheres, olha a gente estranho, vai ver que é porque sabe que os maridos delas vêm aqui" (Jéssica). Esse contexto perpetua um entrave para que a atividade tenha maior suporte legal, como relata Angel:

Eu não ligo para a regulamentação, direito trabalhista. Não aceito, não quero minha carteira assinada. Tem pessoas que 'meu Deus do céu, não chega perto de puta'. Porque acha que puta é aquela vai sair dando para qualquer um, não é assim. A mulher cobra, mas tem gente que ainda tem muito preconceito e pensa: está na minha carteira: 'ah foi garota de programa'. Tipo, se eu for trabalhar em outro lugar, não seria bom. 
Por todo exposto, há evidências que um dos aspectos importantes para extração de sentido advém da remuneração que as profissionais do sexo recebem pelo seu trabalho. Isso mostra que elas não percebem seu trabalho como imoral porque há um pagamento pelo serviço prestado, tornando-o um trabalho como outro qualquer. Esse achado e de que as pesquisadas não encontram prazer no trabalho vão de encontro com os estudos de Hackman e Oldhan (1975), Morin, Tonelli e Pliopas (2007) e Oliveira et al. (2004) de que um trabalho precisa ser moral e dar prazer para ter sentido. Assim, as entrevistadas entendem que o sentido do trabalho está relacionado com a autonomia, remuneração - que é fonte de renda, permite obter objetos de desejo e possibilita a sua sobrevivência e de seus familiares - e desenvolve boas relações de trabalho com colegas, fornecedores e clientes - o mesmo não ocorre com todos os clientes.

\subsection{Contestação moral, o trabalho relacional e o sentido do trabalho}

A moralidade necessária para conferir sentido ao trabalho também advém da estrutura das relações que as profissionais do sexo estabelecem com seus clientes. Neste contexto, as transações financeiras resultantes de relações sexuais exigem o ajustamento entre duas esferas da vida que se misturam nesta troca econômica: a dimensão racional e dimensão afetiva. A análise dos relatos permite evidenciar que, às vezes, estas fronteiras são transgredidas, exigindo um aprendizado constante dos perigos que estas transgressões podem trazer às profissionais. As entrevistadas demonstram ter refletido e feito diversos cálculos para mensurar se os seus possíveis parceiros proveriam o sustento de seus filhos e seriam bons maridos. Essa percepção é ilustrada na fala da Patrícia: "tu sabe que é quase impossível, mas tu sempre quer achar alguém que te salve disso, que cuide de ti, teus filhos. Já vivi com cliente. Não dá certo porque eles não vão querer sustentar os teus filhos, só o deles. Daí tem mulher, família. Dificilmente tu deixa de ser amante".

Nessa mesma direção, Horrana concorda com essa perspectiva: "ter casado com meu cliente foram quatro anos perdidos da minha vida. No começo, ele era um amor de pessoas. Nos últimos dois anos, ele virou minha vida um inferno. Foi a pior coisa que eu fiz na minha vida, ter saído da noite para ficar com ele". Assim, os relacionamentos com clientes também não são vistos com bons olhos pelas entrevistadas, pois "tu gosta, se apaixona, tu sofre. Um dia tu não está lá, ele vai com outra menina e tu sente, dói” (Monique).

Por outro lado, os depoimentos também denotam os múltiplos arranjos que as prostitutas fazem em suas relações com clientes, na tentativa de tecer as boas combinações entre intimidade e atividade econômica (ZELIZER, 2006). Por isso, os limites dentro do circuito econômico onde estas transações ocorrem são constantemente reforçados. O relato de Jéssica mostra os cuidados necessários para evitar que as emoções contaminem a dimensão racional inerente ao exercício da profissão:

Ter romance, não. Só profissional. Tem menina aqui que se apaixona por cliente, tem cliente que se apaixona pela menina. Se a menina é burra, ela dá de graça, perde o foco no objetivo, por isso, tem menina aqui que já faz parte das paredes da boate, não vai sair daqui nunca. A menina que é esperta, ela jamais vai dar de graça porque ela está aqui com um objetivo, né? Tu não veio de tão longe, da tua família, para tu chegar aqui e fazer a burrada de sair ficando e se apaixonando.

O relato de Jéssica mostra a relação com a teoria de que as boas combinações entre racionalidade econômica e o interesse monetário não ameaçam a intimidade, a empatia e as relações de reciprocidade, conforme sugerido por Zelizer (2009, 2012). No que se refere ao relacionamento com cliente, a diversidade das relações é evidente na forma de como profissional do sexo traça os limites das interações. $\mathrm{Na}$ prostituição, as mudanças na demarcação dos limites do circuito onde ocorrem as transações podem sofrer alterações quando a frequência dos encontros aumenta e quando esta relação vai do sexo para a criação de relacionamentos duradouros. Em alguns casos, o casamento surge como forma de consolidação da relação.

As experiências vividas pelas entrevistadas corroboram essa questão, pois já foram casadas com clientes e recebem valores monetários em forma de ajuda e presentes de clientes. Horrana ilustra essa situação: "é que nem o meu cliente agora, ele veio me trouxe um buque de rosas, me deu um dinheiro, 
me levou no banco para depositar. Esse é um cliente fixo, ele já está apaixonado".

As falas de Horrana e Monique mostram que elas investem, com frequência, em relações afetivas com seus clientes. Para ela, estes clientes a tratam muito bem, levando-a para jantar e viajar. Para Monique também é comum receber presentes e flores, bem como auxílio financeiro para pagar as contas: "às vezes, tu até fica mais amigo, começa a ir direto, daí te ajuda a pagar um talão de luz, uma compra no mercado". Na mesma direção, percebeu-se que as entrevistadas permitem a ampliação da relação na perspectiva de intensidade e durabilidade para assumir outro status profissional, como ilustra a fala de Mônica: "eu sou tratada como amante, eles vem, me ajudam um pouco, me levam para sair. Até viajo".

Entretanto, o investimento em uma relação aparentemente perigosa porque mistura afetividade com as transações monetárias, parece estar bem ajustada. Quando Horrana afirma que "ele já está apaixonado" e quando Mônica relata assumir papel de amante, percebe-se uma habilidade por parte das profissionais para permitir um distanciamento suficiente entre uma relação despersonalizada e um envolvimento afetivo que pode causar sofrimento.

Estas falas mostram como emerge e se estrutura o circuito econômico que 'abriga' as relações entre a profissional do sexo e seu cliente, tornando-se um exemplo das configurações complexas que os laços sociais produzem para ajustar o 'lugar' do dinheiro nas relações (Zelizer, 2012). Assim, este estudo concorda com perspectiva teórica de que o circuito econômico é um recurso analítico que permite configurar a circulação de acordos, práticas, informações, instrumentos de troca e símbolos partilhados pelos envolvidos em uma relação.

Ademais, essa análise permite entender que são os envolvidos na transação que definem o conteúdo moral e os limites deste circuito, dando sentido ao trabalho percebido como imoral pela sociedade. Corrobora-se, assim, as sugestões de Zelizer (2006) e França (2014) de que no mercado do sexo, essa demarcação assume múltiplos arranjos que o profissional do sexo precisa fazer com clientes e com parceiros para estabelecer 'boas combinações' entre dinheiro e afetividade.
A configuração adotada no circuito permite que os laços entre o profissional do sexo e seu cliente extrapolem a relação sexual para criação de uma intimidade que compartilha segredos, frustrações e expectativas dos clientes. Para Rubi, isso faz parte da profissionalização do seu trabalho, pois a "garota de programa, não á mais aquela que espera cliente de lingerie na porta da casinha com luz vermelha. Hoje, nós somos psicólogas, porque o cliente não vem só em busca de sexo, ele quer carinho, atenção".

Por todo exposto, o estudo mostra três considerações importantes. A primeira consideração é de que a demarcação do que é aceito moralmente é definido pelos envolvidos na transação. A segunda consideração é que são os laços de intimidade que permitem criar a confiança e a reciprocidade necessárias para que a relação seja bem ajustada pelos envolvidos. Reitera-se, então, a ideia de intimidade de Zelizer (2000) que sugere que a confiança, a reciprocidade e a amizade criam o suporte para a circulação de informações confidenciais, exigindo um trabalho relacional permanente para o ajuste dos limites entre o aceitável e o imoral (ZELIZER, 2009). E, a terceira consideração é que se percebe uma relação entre sentido do trabalho e relações bem ajustadas, uma vez que não somente a satisfação com o trabalho, mas também a moralidade extraída da prática profissional precisa de um ambiente onde circulam códigos e práticas justificadas e que refutam a imputação moral que a sociedade impõe sobre esta profissão. As boas combinações arranjadas nestes circuitos oferecem, portanto, o conteúdo moral necessário para que a relação entre moralidade e sentido do trabalho se estabeleça.

\section{CONSIDERAÇÕES FINAIS}

Este estudo teve como objetivo analisar o sentido do trabalho para as profissionais do sexo visto a imoralidade social do seu trabalho percebida pela sociedade à luz de boas combinações entre as transações econômicas e intimidade que circulam nas relações de trabalho. As percepções das entrevistadas nesta pesquisa mostram que o sentido do trabalho está voltado para a sobrevivência por meio da subsistência do núcleo familiar, mas não para sua autorrealização, 
uma vez que todas as entrevistadas dizem permanecer na prostituição por lograrem a esperança de levantar o capital necessário que lhes garanta uma vida estável. Quanto ao caráter moral associado ao trabalho como profissional do sexo, as entrevistadas reconhecem o preconceito da sociedade, no entanto, isso não impede que o seu trabalho possua sentido.

Essa dicotomia acompanha a discussão de gênero que separa as mulheres em 'boas' e 'más', não considerando, como salienta Corregido (2004), que a mulher ao optar por ser prostituta não deixa de desempenhar papéis atribuídos às demais mulheres na sociedade, ou seja, as tidas como 'boas'. A sociedade as percebe como ávidas por sexo, vagabundas, mulheres de vida fácil, esquecendo que por trás do trabalho da prostituta existem filhos, mães, netos, uma família da qual tem de cuidar, uma perspectiva de futuro (SILVA et al., 2013). Logo, assumem os mesmos papéis concernentes às demais mulheres na sociedade, independente da condição moral do seu trabalho.

Na prostituição, o circuito econômico é representado através da relação do profissional do sexo e o cliente, cabendo a ele a mediação e delimitação das interações, as falhas nesses ajustes e a alteração dessas relações alteram as relações econômicas. Várias formas de ajustes foram percebidas no estudo: em relatos enfáticos sobre o caráter profissional de seu trabalho; nos relacionamentos afetivo-sexuais mantidos com clientes; bem como as estratégias coletivas para garantirem a segurança do grupo. Isso indica que nesse circuito, onde relações íntimas são mediadas pelo dinheiro, ele não surgiu como solvente das relações sociais, corrompendo ou contaminando a empatia e a solidariedade, desta forma, não corroborando a teoria de 'esferas separadas' e 'mundos hostis'.

Chama-se atenção para o insucesso das relações afetivo-sexuais com conjugalidade entre as profissionais do sexo entrevistadas e cliente culminado em seu posterior retorno à prostituição, demonstrando que transações econômicas e intimidade coexistem sem se opor, mas que essa coexistência não está isenta de conflitos e consequências. Por conseguinte, que os arranjos entre intimidade nem sempre são exitosos e relações podem ser destruídas pelo dinheiro. A relação romântica entre o profissional e o cliente é um tema que carece de ser explorado em virtude de sua possível relação com uma série de valores tradicionais e homogeneizantes, como por exemplo, o ideal de amor romântico, do homem como provedor do núcleo familiar.

Por todo exposto, foi possível observar no estudo variações que poderiam ser atribuídas à idade, diferentes momentos de vida dos entrevistados e diferentes locais de exercício da profissão. Nesse aspecto, seria relevante investigar o sentido do trabalho para profissionais do sexo em diferentes gêneros e como estes profissionais ajustam as relações econômicas perpassadas pela intimidade, pois a questão gênero pode ser diferencial em temas como identidade, independência, satisfação pessoal e inserção social.

Ademais, o estudo com profissionais do sexo poderia também ser comparado com outros profissionais autônomos na busca de temas recorrentes de sentido para o trabalho, relações de trabalho e atividades que envolvem trocas econômicas e íntimas, bem como em profissões com baixo prestígio social (empregados domésticos, cabelereiros, manicures) e em pessoas que exercem atividades ilegais.

Entre os aspectos que conferem sentido ao trabalho, o estudo priorizou a análise da relação entre a profissional do sexo e do cliente. Esta opção não permitiu explorar, por exemplo, a relação entre as profissionais que atuam neste mercado. Como, por exemplo, o estudo encontrou evidências de estratégias coletivas para preservação e segurança das profissionais, mas não discutiu se estas estratégias conferem sentido ao trabalho. Estudos futuros podem seguir esta trilha para ampliar os efeitos das relações sociais para conferir sentido ao trabalho das profissionais do sexo.

\section{REFERÊNCIAS}

ARRUDA, J. R. et al. Carreira desviante: prostitutas e a sua relação com o Núcleo de Estudos da Prostituição (NEP). In: Semana Científica Do Unilasalle Canoas, 13., 2017, Canoas. Anais... Canoas: SEFIC, 2017.

BARDIN, L. Análise de conteúdo. 3.ed. Lisboa, Portugal: Edições 70, 2009. 
BENOIT, C. et al. Prostitution stigma and its effect on the working conditions, personal lives, and health of sex workers. The Journal of Sex Research, v. 55, n. 4-5, p. 457-471, 2017.

BURBULHAN, F.; GUIMARÃES, R. M.; BRUNS, M. A. T. Dinheiro, afeto, sexualidade: a relação de prostitutas com seus clientes. Psicologia em Estudo, v. 17, n. 4 , p. $669-67717,2012$.

CARRASCO, M. et al. We talk, we do not have shame: Addressing stigma by reconstructing identity through enhancing social cohesion among female sex workers living with HIV in the Dominican Republic. Culture, Health, and Sexuality, v. 19, p. 543-556, 2017.

CARVAlho, R. S.; Oliveira, J. M. C. Regulamentação da Prostituição no Brasil. Revista Jurídica Direito, Sociedade e Justiça, v. 6, 2018.

CHAPKIS, W. Live Sex Acts: women performing erotic labor. New York: Routledge, 1997.

BRASIL. Classificação Brasileira de Ocupações. Nova Classificação Brasileira de Ocupações. 2002. Disponível em: <http://www.mtecbo.gov.br/cbosite/ pages/pesquisas/BuscaPorTituloResultado.jsf $>$. Acesso em: 24 abr. 2018.

CORRÊA, W. H.; HOLANDA, A. F. Prostituição e sentido de vida: relações de significado. Psico-USF, v. 17, n. 3, p. 427-435, 2012.

CORREGIDO, M. D. J. El peso de la discriminación: debates teóricos e fundamentaciones. In: OSBORNE, R. (Ed). Trabajadoras del sexo: derechos, migraciones y tráfico en El siglo XXI. Barcelona: Bellaterra, 2004.

EDWARDS, S. The legal regulation of prostitution: a human rights issue. In: SCAMBLER, A.; SCAMBLER, G. (Ed.). Rethinking prostitution: Purchasing Sex in the 1990s. London and New York: Routledge, 1997.

ERTMAN, M. M. For both love and money: Viviana Zelizer's The Purchase of Intimacy. Law \& Social Inquiry, v. 34, n. 4, p. 1017-1037, 2009.
FRANÇA, M. V. Intimacy's Ups and Downs on the Stairs of Belo Horizonte's Red Light District. Cadernos Pagu, v. 4, p. 321-346, 2014.

Práticas e sentidos da aprendizagem na prostituição. Horizontes Antropológicos, v. 47, p. 325-349, 2017.

HACKMAN, J. R.; OLDHAM, G. R. Development of the job diagnostic survey. Journal of Applied psychology, v. 60, n. 2, p. 159, 1975.

KOKEN, J. Independent female escort's strategies for coping with sex work related stigma. Sexuality \& Culture, v. 16, n. 3, p. 209-229, 2012.

LYONS, T. et al. Negotiating violence in the context of transphobia and criminalization. Qualitative Health Research, v. 27, p. 182-190, 2017.

MARSHALL, C. E.; MARSHALL, I. H. Prostitution in the Netherlands: It's Just Another Job! In: CULLIVER, C. (Ed.). Female criminality: the state of art. New York, London: Garland Publishing, 1993.

MOLINA, A. M. R.; KODATO, S. Trajetória de vida e representações sociais acerca da prostituição juvenil segundo suas participantes. Temas em Psicologia, v. 13, n. 1, p. 09-17, 2005.

MORIN, E. M. Os sentidos do trabalho. Revista de administração de empresas, v. 41, n. 3, p. 8-19, 2001.

MORIN, E. M.; TONELLI. M. J. ; PLIOPAS, A. L. V. O trabalho e seus sentidos. Psicologia \& Sociedade, v. 19, n. 1, p. 47-56, 2007.

NASCIMENTO, R. L.; SANTOS, A. S. L.; PINTO, A. P. M. O Sentido do Trabalho para o Agente Funerário. In: Encontro da Associação Nacional de Pós-Graduação em Administração, 41., 2017, São Paulo. Anais... São Paulo: ANPAD, 2017.

OLIVEIRA, S. R. et al. Buscando o sentido do trabalho. In: Encontro Nacional da Associação Nacional de Pós-Graduação e Pesquisa em Administração, 28., Curitiba, 2004. Anais... Curitiba: ANPAD, 2004. 
PAULI, J.; ROSENFIELD, C. A função do dinheiro: uma análise das estratégias dos mediadores em um sistema de crédito cooperativo. Sociedade e Estado, v. 32, n. 1, p. 171-188, 2017.

PELÚCIO, L. Desejos, brasilidades e segredos: o negócio do sexo na relação entre clientela espanhola e travestis brasileiras. Bagoas-Estudos gays: gêneros e sexualidades, v. 5, n. 06, 2012.

ROBERTS, N. As prostitutas na história. Rio de Janeiro: Record Rosa dos Tempos, 1998.

RODRIGUES FILHO, L. Prostituição: um estudo sobre as dimensões de sofrimento psíquico entre as profissionais e seu trabalho. Revista Científica da UEM: Série Ciências da Educação, v. 1, n. 1, p. 114-123, 2014.

RODRIGUES, A. L.; BARRICHELLO, A.; MORIN, E. M. Os sentidos do trabalho para os profissionais de enfermagem: um estudo multimétodos. Revista de Administração de empresas, v. 56, n. 2, p. 192208, 2016.

RODRIGUES, M. T. A prostituição no Brasil contemporâneo: um trabalho como outro qualquer? Revista Kátalysis, v. 12, n. 1, p. 68-76, 2009.

. Prostituição e feminismo. In: BOSCHETTI, I.; BEHRING, E. (Ed.). Capitalismo em Crise: Política Social e Direitos. São Paulo: Cortez Editora, 2010.

RUSSO, G. No labirinto da prostituição: o dinheiro e seus aspectos simbólicos. Caderno CRH, v. 20, p. 497-514, 2007.

SANDERS, T. Unpacking the process of destigmatization of sex worker/ers: Response to Weitzer "Resistance to sex work stigma". Sexualities, p. 1-4, 2017. Disponível em: <http://journals.sagepub.com/ doi/pdf/10.1177/1363460716677731>. Acesso em: 10 mar. 2018.
SIlVA, K. A.; CAPPElle, M. C. Sentidos do Trabalho Apreendidos por meio de Fatos Marcantes na Trajetória de Mulheres Prostitutas. Revista de Administração Mackenzie, v. 16, n. 6, p. 19-47, 2015.

SILVA, K. A et al.. Ser Prostituta: o Sentido do Trabalho Moralmente Inaceitável. Revista Gestão Organizacional, v. 11, n. 2, p. 215-246, 2013.

SOARES, J. F. S. et al. Prostituição como profissão: uma análise sob a ótica das profissionais do sexo. Revista Saberes, v. 3, n. 2, p. 63-75, 2015.

SOUZA, F. R. Saberes da vida na noite: percepções de mulheres que prestam serviços sexuais sobre o educar-se nas relações com seus clientes. Dissertação (Mestrado em Educação) - Centro de Educação em Ciências Humanas, Universidade Federal de São Carlos, São Carlos, SP, Brasil, 2007.

STEINER, P.; TRESPEUCH, M. Marchés contestés. Quand le marché rencontre la morale. Toulouse, Presses universitaires du Midi, 2014. 344 p.

TOLFO, S. R.; PICCININI, V. Sentidos e significados do trabalho: explorando conceitos, variáveis e estudos empíricos brasileiros. Psicologia \& Sociedade, v. 19, p. 38-46, 2007.

WEITZER, R. Resistance to sex work stigma. Sexualities, p. 1-13, 2017. Disponível em: <http://journals.sagepub.com/doi/ pdf/10.1177/1363460716684509 >. Acesso em: 01 mar. 2018.

ZELIZER, V. A. The purchase of intimacy. Law \& Social Inquiry, v. 25, n. 3, p. 817-848, 2000.

Intimité et économie. Terrain Anthropologie \& sciences humaines, n. 45, p. 13 28, 2005.

Money, power, and sex. Yale JL \& Feminism, v. 18, p. 303, 2006. 
Pasados y futuros de la sociología económica. Apuntes de Investigación del CECYP, n. 14, p. 95-112, 2008.

Dinheiro, poder e sexo. Cadernos

Pagu, v. 32, p. 135-157, 2009.

. How I became a relational economic sociologist and what does that mean?. Politics \&

Society, v. 40, n. 2, p. 145-174, 2012. 